\title{
Planning for a new sustainable city in Iran: a case study of Mahmoodabad, Mazandaran
}

\author{
H. Farzaneh \\ Mahmoodabad City Council, Iran
}

\begin{abstract}
The city of Mahmoodabad is located in the south of the Caspian Sea and is the nearest coastal town to Tehran, the capital of Iran. This city is trying to become a sustainable city, in different aspects of sustainable development, socially, economically and environmentally. The process requires the participation of inhabitants as well as the support of national and local government. Therefore, the City Council seeks to design a strategic and scientific planning as a guideline through the Framework of Strategic Sustainable Development (FSSD). The main purpose of the project is a practical plan for implementing. For doing this, this paper explores the main challenges that have been presented by inhabitants and local authorities, brainstorms possible actions and ideas and prioritizes these actions based on local resources and capacities. Then, it presents a social actions model for citizens to participate in.

Keywords: $\quad$ strategic sustainable development, sustainability challenges, sustainability solutions, social sustainability, City Council, Mahmoodana, Mazandaran, Iran.
\end{abstract}

\section{Introduction}

Over the past few decades, Iran has experienced economic and social growth; however there has been a dramatic upsurge in environmental degradation [1]. The country and its cities now face many sustainability challenges. Focuses on sustainability issues in Mahmoodabad, The key questions are what are the most important sustainability issues, the main barriers and enablers of sustainability strategies, the major actions and visions to overcome these problems and how to actualize the main actions to move city from the existing less-sustainability state to the desirable future. 
This paper presents the Framework of Strategic Sustainable Development (FSSD) to analyze. Therefore, in the first phase, the main concepts of this framework will introduce and then, this sustainability challenge will be considered based on FSSD. Finally, it will try to design a sufficient and practical model to lead by City Council as the main responsible vehicle and NGOs in society and small communities, as well.

\section{The Framework for Strategic Sustainable Development}

The Framework for Strategic Sustainable Development (FSSD) was created by Karl-Henrik Robèrt to provide an obvious and deep description of a sustainable society [2] by defining basic principles to society in order to understand what not to do. These principles focus on ecological and social sustainability.

The 4 sustainability principles (4 SPs) that define sustainability in the FSSD are: "in a sustainable society, nature is not subject to systematically increasing:

1. concentrations of substances extracted from the Earth's crust;

2. concentrations of substances produced by society;

3. degradation by physical means [3];

and, in that society

4. people are not subject to conditions that systematically undermine their capacity to meet their needs" [4].

The FSSD consists of 5 levels including system, success, strategic, actions and tools. The 5 levels FSSD create a strategic planning towards sustainability to work strategically and solve sustainability problems within society.

System: The global socio-ecological system (society within the biosphere). An overview of the sustainability challenge.

Success: A society that complies with 4 Sustainability Principles.

Strategic: Backcasting from success (The ABCD Process)/the 3 Prioritization Questions.

Actions: The actions that help move the global socio-ecological system towards sustainability.

Tools: Tools that support efforts to reach global sustainability.

For implementing the FSSD in the real world, the ABCD Process or the Backcasting Process would be considered as a structured and strategic planning tool. Backcasting defines as a process for achieving a desirable future and moving towards a sustainable society.

The 4 steps of the ABCD Backcasting Process are:

A-Step: Awareness/Building a Shared Understanding and Vision.

B-Step: Baseline Assessment/Assessing the Current Reality.

C-Step: Creative Solutions/Brainstorming Possible Actions.

D-Step: Decide on Priorities/Actions Prioritization [4].

A-Step: $\quad$ The shared understanding and vision of success for a sustainable society create in the A-Step of the ABCD Backcasting Process. 
B-Step: In the B-Step, society needs to assess its current reality through the lens of the 4 Sustainability Principles for developing a detailed baseline assessment and also, to identify opportunities and strengths.

C-Step: In this step, a list of creative ideas, actions and solutions are generated in a brainstorming process to move society towards sustainability.

D-Step: Using a strategic prioritization process to prioritize the brainstormed actions with 3 Prioritization Questions to be more efficient and effective:

- $\quad$ Right Direction: Does this action idea move society towards sustainability?

- Flexibility: Does this action idea provide for flexibility when moving towards sustainability?

- Good Return Investment: Does this action idea provide a sufficient return on investment of collective time, financial, labor, etc. efforts? [5].

As mentioned, the FSSD provides a strategic planning and holistic perspective for sustainable development in a complex socio-ecological system [6] and The ABCD Process helps this process to be more practical and operational.

\subsection{Awareness of sustainability}

For considering the sustainability challenges and moving towards sustainability, a society should have a vision of sustainable society by defining shared vision and success.

Sustainable Development defined based on an agreed definition of the United Nations Conference (Brundtland Report) as: "Sustainable development is development that meets the needs of the present without compromising the ability of future generation to meet their own needs" [7].

Sustainable development encompasses environmental, economic and social sustainability. In addition to balancing and integrating these 3 components of community $[8,9]$, in the sustainable society, "the needs of all individuals and societies should be met, within the constraints imposed by the biosphere; and all should have equal opportunity for improving their lot" [10]. Therefore, "Sustainability is important to ensure that the social, environmental and economic systems that make up our resort community are providing a healthy and meaningful life for residents and visitors alike" [11].

Commitment to sustainability principles and goals is a key factor for achieving a better future; and finding, adapting and solving solutions to social challenges.

So, Iranian experts, decision-makers, government and especially city council have to schedule the strategies and plans based on sustainable development definition and principles to answer these critical and problematic conditions, and stop doing or doing some actions for a better world. In this process, awareness of people and a shared vision of a sustainable society can help to move rapidly towards sustainability. 


\subsection{Present reality}

For solving the sustainability challenge in a complex system, it is necessary to analyze and assess the current situations, as well. Hence, this paper starts with a short description of Mahmoodabad status.

Geographically, Mahmoodabad is a city in Mazandaran Province in the north of Iran and located on the southern coast of Caspian Sea. Agriculture and aquaculture play the important roles in the economy. Tourism industry is another main part of economy in the region and Iranian always appreciate to visit the area because of beautiful beaches and great weather.

In addition to local problems that has increased significantly, there are some issues in related to tourism industry, like environmental issues.

Unemployment, financial problems and low investment, waste, water pollution, sewage problems, traffic, deforestation, lack of transparency, low social capital and low cohesion, dissatisfaction with the services provided by the local offices such as municipality are some of the most important issues in Mahmoodabad.

\subsection{Creative solutions}

Possible actions and ideas will brainstorm in two ways. At first, these ideas will create based on local barriers and then, in conjunction with global solutions. Certainly, in some cases there are overlaps between the 2 brainstorm ways.

By considering these actions and ideas to be implemented and practical, these must reflect global policies in terms of national resources and capacities. These actions choose based on the 3 Prioritizing Questions of Right Direction; Flexible Platform and Return on Investment.

Ideas can arrange onto the 4 major categories of environmental, culturalsocial, urbanism and economic. Also, these actions can prioritize in Short ( 1 year), Medium (2-3 years), and Long (more than 3 years) term actions in individual and collective levels.

These proposed actions and ideas about sustainability solutions are approximately sixty of potentially thousands.

\subsubsection{Social-cultural}

- Citizenship education programs

- Increasing awareness of sustainability (long term action);

- Fostering citizen participation (long term action);

- Teaching rights and responsibilities of citizenship (medium term);

- $\quad$ Reinforcing social capital and building trust (long term action).

- Urban research program

- Create and run workshops, organize lectures, seminars, and conferences (short term);

- $\quad$ Assessing urban demands (medium term);

- $\quad$ Taking research surveys (short term).

- Internalization of dialogue principles among citizens

- $\quad$ To form a centre for dialogue (medium term); 
- $\quad$ Create citizens ideas database (medium term);

- Sharing information and experiences with previous mayors and city council members, city experts, practitioners and citizens (medium term);

- Engaging people by participation in city activities (long term).

- City identity

- Design elements of visual identity (medium term);

- Holding traditional rituals, ceremonies and festivals (medium term);

- Opening city history museum (long term);

- Build the City Hall (medium term).

- Sport and recreation

- Developing sport program in neighbourhoods (medium term);

- Expanding sport facilities and places (long term;

- Supporting a range of sports (teams/clubs and athletes) (short term);

- To design cycling and walking paths (short term);

- Holding city competitions between college students or employees (medium term).

- Volunteer activities

- Organize for cleaning forests and beaches, leading tourists and etc. (short term);

- Encouraging elites and the best persons in public services (short term);

- Supporting city charities and NGOs (medium term).

- Art activities

- Present concerts and theatres in the park, especially in the summer and holydays (short term);

- Expending public libraries (long term);

- Opening cinema hall (medium term);

- Organize for wall paintings in the city (short term).

- Women empowerment

- Empowering women through education (long term);

- Encouraging for domestic jobs (long term);

- Hold women's festivals (short term);

- Facilitating for sharing information, ideas and experiences (medium term).

\subsubsection{Economic}

- Investment

- To attract private sector investors based on investment incentives such as law, safety and tax (medium term);

- Strengthen tourism infrastructure with private sector collaboration (long term).

- Employment

- Promoting local economies projects (long term);

- Organize citizen's economic activities (long term).

- Accountability \& Transparency

- Provide municipal GIS (Geographic Information System) services /paperless (long term); 
- $\quad$ Publish a monthly newsletter and create a website (short term);

- $\quad$ Trying to remove corruption and other offences (long term).

\subsubsection{Urbanism}

- Architecture and urban planning

- Considering the identity and authenticity of city and avoid visual disturbances (long term);

- Improve public facilities, urban furniture and sidewalk (long term).

- Tourism infrastructure

- Developing boating and water sports (medium term);

- Provide city forests for visitors (medium term).

- Contracts and agreements

- Signing of agreements with various offices for integrated management in city (medium term).

\subsubsection{Environmental}

- Green spaces

- Create several green belts around the city (short term);

- Create natural boundaries for rivers (medium term);

- Tree planting in all streets differently (short term);

- Extending parks and community gardens (long term);

- Building a children educational park to learn through play (long term).

- Waste and garbage

- Educate public on garbage segregation (long term);

- Recycling (long term);

- Daily handling of waste (short term);

- Providing special centres for paper and bottles (short term);

- Reduce using of plastics bags (medium term).

- Environmental pollutants

- Doing sewage disposal systems (long term);

- Removing water pollution in the lakes and rivers (long term);

- Reducing air pollution by expending public transportation (long term action).

\subsection{Prioritization step}

Members of the City Council know that there are structural, legal, economic and cultural barriers for implementing strategies successfully in the four-year period. For example, financial issues are the most significant barriers. Another barrier is unawareness of sustainability principles and related criteria. In fact, most people aren't aware of sustainability challenges and their hazards. It seems that, this is a major obstacle to participate.

So, in prioritization step and discussing the problem, City Council mainly recommends solutions based on short term actions, especially in environmental aspects because of their hazardous conditions. Also, they prefer to choose some actions in citizen participation rather than the other brainstormed actions due to 3 
prioritizing questions and also, because of more successful than others plans that government has done.

Historically and legally, government has responsibility for environmental stewardship and social and economic fields in Iran. Government's agenda consists of several essential strategies. These long term or temporary solutions were less successful. Hence, it seems that citizen participation is certainly the best way of achieving the desired goals.

The City Council is hoping to increase people's awareness about sustainability challenges and their consequences, particularly in related to meeting their needs and next generations by implementing social sustainability actions to change mindset of people. In other words, it seems that awareness is the key for changing and city needs to aware people about local environmental, economic and social issues, building trust, learning and mutual understanding about sustainability challenges. Citizen participation is the first and the main step and now, the key question is how to develop citizen participation and how to actualize the main actions to move society towards sustainability.

\section{Design a social actions model for citizens}

As mentioned, society suffers from a step-by-step and defined process for community participation that can be implemented by this model.

\subsection{The process of taking actions for sustainable citizenship}

The literature on the social sustainability actions and citizenship points to presents a theoretical and practical approach towards sustainability. This process looks at citizenship through social sustainability lens in a way to try for changing and how take social actions for a sustainable society; after knowing what leading actions sustainability practitioners use to move towards social sustainability.

Guido et al. [12] identified 27 social sustainability actions that practitioners use to move towards social sustainability such as Share Information, Do Engagement Activities, Have a Meeting and Use Education. They also, offered 3 potential universal categories of social sustainability actions. These are: Share, Inspire, and Engage.

This study claims that in connecting to these 3 universal social sustainability actions categories, 3 main areas/levels would be considered. These areas of thinking and implementing indicate levels of implement that citizens need to do. Every level is interconnected and dependent to each other but it seems that each level is increasingly harder to implement than previous ones. This is because higher levels call on complex actions with people for doing. All actions include improving cultural policies, global strategies and local planning.

\section{First: increasing awareness}

"Acknowledging the problem is the first step to doing something" [13]. "Fullan (2001b) argues that for change to be sustainable, participants must come to a clear shared understanding of the meaning of change. Hargreaves and Fink 
(2003), Tyack and Cuban (1995), and Cole (2001) appear to have a greater tolerance for ambiguity. They argue that committed participation in and ongoing attention to change must accompany ongoing evaluation and reconsideration of the meaning of innovations as the complex contexts in which change is initiated also undergo change" [14] but, what knowledge of sustainability for increasing awareness is needed to care about them, to be aware them.

It seems that considering the global sustainability challenges; and the other hands, local sustainability issues could create a mindset of thinking and taking actions.

So, this step would be start in knowing and understanding of global and local problems through knowing information and sharing knowledge and experiences to strengthen and empower and take actions for a sustainable society.

Also, prerequisites for sustainability and transition could be related with religious and national heritage in Iran. It can be considered as an opportunity because a huge challenge in transition process is that changes at the cultural dimension usually take place slowly and also, at the landscape level [15]. So, City Council can emphasize to common concepts in religion and sustainability principles. In this case, people's awareness increase; they can accept easily at the micro level and play a responsible role in a sustainable world.

\section{Second: internalizing}

Internalization refers the long term process of deep and inner change of perspective, values and behavior culturally and personally through social learning.

This process "make (attitudes or behavior) part of one's nature by learning or unconscious assimilation" [16] to understand, accept and finally becomes an inner control. It can lead to greater awareness and empathy amongst citizens.

"Building on the presence of social capital, social cohesion involves the internalization of social ethics and constitutes the level of realized propensity among citizens to engage in virtuous behavior for the common good" [17].

\section{Third: practicing}

Sustainable citizens need doing principles on human rights and the environment. They should experience these principles in their daily lives at home, school, and society. This level should create strategies for citizens. Most of these actions mentioned before as brainstormed actions.

Link to bottom-up paradigm [18], this is based on a participatory philosophy. This "frameworks depart from traditional scientific methods and suggest that local stakeholders should be the chief actors in choosing relevant indicators" [19] and using participatory tools to achieve the goals of sustainability and balance between societies and higher order principles and actions by fostering of participatory and collaborative process through sharing responsibilities, sharing information, team work, learning and training. In other words, in this process everyone has a crucial role in the society by respecting the mutual rights and responsibilities and trying to solve the problem. 
It is important to note that the participatory and ongoing process would be more efficient, if it be commitment to 4 characteristics of social sustainability actions (Observe, Listen, Dialogue and Feel) [12].

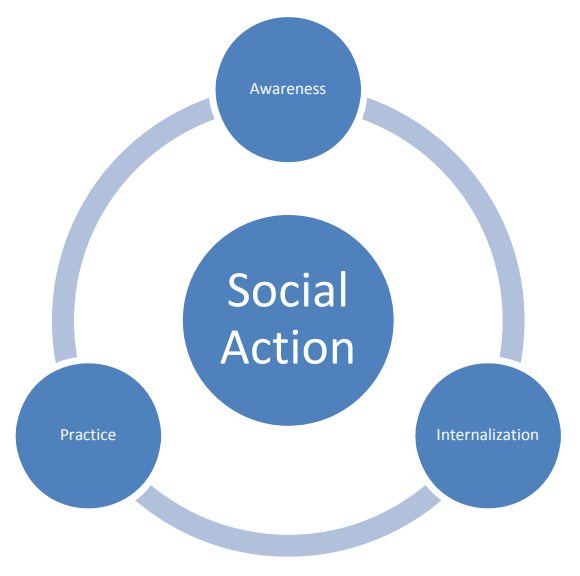

Figure 1: Three areas of social actions.

\section{Conclusion}

As concluded, sustainability challenges are problematic and unknown issues in Iran. Efforts of government have been little success. So, Mahmoodabad City Council is trying to present a sustainable city in the four-year period by knowing problems and brainstorming possible actions to prioritize the efficient actions. Also, the members of City Council want to engage citizen through a social action model. They believe that the deep gap between lack of awareness and unsuccessful strategies will be filled by empowerment of active people on long term actions. Certainly, citizen participation will enhance environmental protection and social commitment in one of the most beautiful city in Iran, Mahmoodabad.

\section{References}

[1] The World Bank, www.data.worldbank.org/country/iran-islamic-republic

[2] Robèrt, K-H., Tools and concepts for sustainable development, how do they relate to a general framework for sustainable development, and to each other? Journal of Cleaner Production, 8(3), pp. 243-254, 2000.

[3] Holmberg, J., Lundqvist, U., Robèrt, K-H. \& Wackernagel, M., The Ecological Footprint from a Systems Perspective of Sustainability. International Journal of Sustainable Development and World Ecology, (6), pp. 17-33, 1999. 
[4] Ny, H., MacDonald, J. P., Broman, G., Yamamoto, R. \& Robèrt, K-H., Sustainability constraints as system boundaries- An approach to making life-cycle management strategic, Journal of Industrial Ecology, 10(1-2), pp. 61-77, 2006.

[5] Holmberg, J. \& Robèrt, K-H., Backcasting from non-overlapping sustainability principles- a framework for strategic planning, International Journal of Sustainable Development and World Ecology, (7), pp. 291-308, 2000.

[6] Robèrt, K-H., Schmidt-Bleak, B., Aloisi de Larderel, J., Basil, G., Jansen, J. L., Kuehr, R., Price Thomas, P., Suzuki, M., Hawke, P., \& Wackernagel, M., Strategic sustainable development - selection, design and synergies of applied tools, Journal of Cleaner Production, 10(3), pp. 197-214, 2002.

[7] World Commission on Environment and Development (WCED), Our Common Future, Oxford University Press: Oxford, 1987.

[8] Colantonio, A., Social Sustainability: An Exploratory Analysis of its Definition, Assessment, Methods, Metrics and Tools. In: Measuring Social Sustainability: Best Practice from Urban Renewal in the EU 2007/01: EIBURS Working Paper Series. Oxford Institute for Sustainable Development (OISD), International Land Markets Group, Oxford Brookes University, Oxford: UK, 2007.

[9] Colantonio, A., Social Sustainability: Linking Research to Policy and Practice. Oxford Institute for Sustainable Development (OISD), Oxford Brookes University, Oxford: UK, 2009.

[10] Tilbury, D., Stevenson, R. B., Fien, J. \& Schreuder, D., Education and Sustainability; Responding to the Global Challenge, IUCN Commission on Education and Communication (CEC), IUCN - The World Conservation Union, 2002.

[11] Why is sustainability important? Whistler 2020, Moving Toward a Sustainable Future, www.whistler2020.ca/whistler/site/genericPage.acds? context $=1967862$ \&instanceid $=1967863$

[12] Guido, A., Farzaneh, H. \& Guo, J., Social Actions of Strategic Sustainable Development, Thesis, School of Engineering Blekinge Institute of Technology, Karlskrona: Sweden, 2012.

[13] Marcum, J. W., Sustainability by engagement: The Bottom Line, Managing Library Finances, 22(3), pp. 76 -78, 2009.

[14] Nocon, H, D., Sustainability as Process: Community Education and Expansive Collaborative Activity, Educational Policy, 18(5), pp. 710-732, 2004.

[15] (Hans) de Haan, J. \& Rotmans, J., Patterns in transitions: Understanding complex chains of change, Technological Forecasting and Social Change, 78(1), pp. 90-102, 2011.

[16] Oxford Dictionaries, Internalize, Oxford University Press, www.oxforddictionaries.com/definition/internalize? $q=$ internalizations\#int ernalize 
[17] Heuser, B. L., The Ethics of Social Cohesion, Peabody, Journal of Education, 80(4), pp. 8-15, 2005.

[18] Bell, S. \& Morse, S., Breaking through the Glass Ceiling: who really cares about sustainability indicators? Local Environment, 6(3), pp. 291-309, 2001.

[19] Reed, M. S., Fraser, E. D.G. \& Dougill, A. J., An adaptive learning process for developing and applying sustainability indicators with local communities, Ecological Economics, 59(4), pp. 406-418, 2006. 